\title{
Factors Associated with the Use of Intermittent Preventive Treatment (IPTp) by Women During Pregnancy in Burkina Faso
}

\author{
Aristide Romaric Bado ${ }^{1,2, *}$, Hermann Badolo ${ }^{3,4}$, Mwinonè Hervé Hien ${ }^{1,3}$, Ibrahim Lougué , \\ Sathiyasusuman Appunni ${ }^{4}$, Nicolas Méda ${ }^{6}$ \\ ${ }^{1}$ Department of Biomedical and Public Health, Research Institute of Health Science, Ouagadougou, Burkina Faso \\ ${ }^{2}$ West African Health Organization (WAHO), Bobo-Dioulasso, Burkina Faso \\ ${ }^{3}$ National Institute of Public Health, Ouagadougou, Burkina Faso \\ ${ }^{4}$ Department of statistics and Population studies, University of the Western Cape, Cape Town, South Africa \\ ${ }^{5}$ Burkinabe Association for Family Welfare, Ouagadougou, Burkina Faso \\ ${ }^{6}$ Department of Public Health, Faculty of Medicine, University Joseph Ki-Zerbo, Ouagadougou, Burkina Faso \\ Email address: \\ arbado@gmail.com (A. R. Bado), badholobi@gmail.com (H. Badolo), hien_herve@hotmail.com (M. H. Hien), \\ lougue.ibrahim12@gmail.com (I. Lougué), sappunni@uwc.ac.za (S. Appunni),nicolas.meda@gmail.com (N. Méda) \\ ${ }^{*}$ Corresponding author
}

\section{To cite this article:}

Aristide Romaric Bado, Hermann Badolo, Mwinonè Hervé Hien, Ibrahim Lougué, Sathiyasusuman Appunni, Nicolas Méda. Factors Associated with the Use of Intermittent Preventive Treatment (IPTp) by Women During Pregnancy in Burkina Faso. World Journal of Public Health. Vol. 6, No. 3, 2021, pp. 110-120. doi: 10.11648/j.wjph.20210603.15

Received: July 9, 2021; Accepted: August 4, 2021; Published: August 12, 2021

\begin{abstract}
Introduction: Malaria infection during pregnancy is more pronounced in endemic areas of sub-Saharan Africa and is a major risk factor for maternal and child morbidity and mortality. Intermittent preventive treatment in pregnancy (IPTp) is presented as an effective way of combating malaria. This study aims to identify the different factors that may influence the use of IPTp by pregnant women in Burkina Faso. Methods: The data used in this study were derived from two rounds of the Malaria Indicator Surveys (MISs) conducted in Burkina Faso in 2014 and 2017. The sample for this study consisted of women aged 15-49 years who had had a live birth in the two years prior to the survey and who might or might not have received IPTp doses. Data analysis was performed using the Stata 15 software. Bivariate analysis and a logistic regression model were used to determine the associated factors. Results: The study results show that $56 \%$ and $63 \%$ of pregnant women had received at least three or more doses of IPTp during pregnancy in 2014 and 2017, respectively. For the 2014 survey, religion, education level, household standard of living, region of residence and type of caregiver were the significant factors associated with receiving three or more doses of IPTp, while those in the 2017 survey were household standard of living, region of residence and access to malaria information. Conclusion: Plausible interventions to increase the reception of at least three doses of IPTp during pregnancy by explaining the benefits of SP could help to effectively control malaria in women and thus increase foetal and infant survival at birth.
\end{abstract}

Keywords: Determinants, Intermittent Preventive Treatment (IPTp), Malaria, Pregnancy, Chemoprevention, Burkina Faso

\section{Introduction}

Morbidity and mortality caused by malaria infection during pregnancy are most pronounced in endemic regions of sub-Saharan Africa [1]. In this part of the world, malaria infection during pregnancy is a major risk factor for maternal and infant morbidity and mortality [2]. It causes maternal anaemia, which, when severe, increases the risk of maternal death [2, 3]. It can also lead to low birth weight [3] and congenital infection and increase the risk of miscarriage and stillbirth $[1,2]$. In view of the serious health consequences of malaria for mother and child, the World Health Organization 
(WHO) recommends a three-pronged approach to malaria prevention during pregnancy in areas of stable malaria transmission in Africa. This approach is based on the use of chemoprophylaxis and insecticide-treated bed-nets and the appropriate management of malaria cases in pregnant women $[4,5]$.

The efficacy of intermittent preventive treatment during pregnancy (IPTp) has been shown by several previous studies [6-8]. Indeed, a review of the literature summarised the results of various randomised or quasi-randomised studies. Its conclusions underline the fact that the use of IPTp in pregnant women reduces clinical episodes of malaria, parasitaemia and placental infection at birth [6-8].

The World Health Assembly adopted the strategy in May 2015 and set the target of reducing the global malaria burden and mortality rates by at least $90 \%$ by 2030 . The strategy emphasises the need to achieve universal coverage of basic malaria interventions for all at-risk populations and the importance of using high-quality surveillance data for decision-making [9]. For example, in 2015, it recommended treatment with three or more doses of IPTp in areas of stable malaria transmission for all malaria-endemic countries.

In Burkina Faso, malaria remains a stable endemic throughout the country, with a seasonal peak (May to October) and also remains the leading cause of morbidity and mortality. The disease is the leading cause of consultation in health centres. In 2018, 26,353,768 consultations were recorded in basic health facilities, and $41.3 \%$ of these consultations were related to malaria [10]. Children under five years of age and pregnant women are vulnerable populations who pay a heavy price in terms of malariarelated morbidity and mortality. Following WHO recommendations, in 2005, Burkina Faso adopted a new treatment policy with the introduction of Artemisinin-based combination therapy (ACTs) and IPTp with sulfadoxinepyrimethamine (SP) in pregnant women. All pregnant women must have at least three doses of IPTp during prenatal consultations. Results from the 2014 and 2017 Malaria Indicator Surveys (MISs) show that only 22\% [11] and 58\% [12] of women, respectively, aged 15-49 with a live birth in the two years prior to the surveys had received at least three doses of SP/Fansidar for malaria prevention during pregnancy. The trend is upward, and a greater knowledge of the factors associated with receiving three or more doses of IPTp is needed to enable policymakers to determine appropriate solutions to improve malaria prevention coverage in Burkina Faso.

In the literature, four groups of factors have been reported to directly or indirectly influence the observance of IPTp by pregnant women: sociocultural characteristics that determine the social and economic status [13], demographic characteristics, knowledge [5], attitudes and practices (KAP) with regard to malaria and the quality of antenatal consultations in health centres [14]. It is in this sense that this study was conducted, with the objective of identifying the factors associated with the use of IPTp by women during pregnancy in Burkina Faso and examining how these determinants evolved between 2014 and 2017.

\section{Materials and Methods}

\subsection{Data Source}

The data used for this study were derived from two rounds of the MISs conducted in Burkina Faso in 2014 and 2017. These surveys were conducted by the National Institute of Statistics and Demography of Burkina Faso in collaboration with the National Malaria Control Programme, with technical assistance from Macro International. The main objective of the 2014 and 2017 MISs was to provide updated estimates of basic malaria-related indicators. During these surveys, information was collected on vector control interventions, such as the use of impregnated mosquito nets and indoor residual spraying, on IPTp of malaria in pregnant women, on care-seeking and treatment of fever in children and finally on knowledge of malaria and the means of prevention.

Both surveys used a nationally representative sample. A total of 6,448 households and 6,322 households were surveyed in 2014 and 2017, respectively. These samples were selected using a two-stage stratified cluster design, with enumeration areas as sampling units for the first stage and households for the second stage. All women aged 15-49 who were either permanent residents of the selected households or visitors who stayed in the households were interviewed.

\subsection{Population Concerned}

The sample for this study consisted of women aged 15-49 years who had had a live birth in the two years prior to the survey and who, during the pregnancy leading to the last live birth, had received or had not received doses of SP/Fansidar.

In the 2014 survey, 8,111 women aged 15-19 were surveyed, 4,824 of whom had had a live birth in the two years prior to the survey. In the 2017 survey, 7,628 women aged 15-49 were surveyed, 4,504 of whom had had a live birth in the two years prior to the survey.

\subsection{Questionnaire}

Two questionnaires were used during the survey: a household questionnaire and an individual questionnaire for women aged 15-49. The individual women's questionnaire collected information in the following five areas: (1) women's sociodemographic characteristics (age, level of education, literacy, etc.); (2) history of reproduction, including recent births and the woman's current pregnancy status: this information was used to identify women who had had recent pregnancies and children under five years of age; (3) IPTp: this section was only for women who had had a birth in the last five years (they were asked whether they had received antenatal care and whether they had received preventive treatment for malaria during their last pregnancy); (4) fever and treatment: this section was addressed only to women who had had a live child born in the last six years (if so, they were asked, for each child, whether he/she had had a fever recently and, if so, whether and how he/she had been 
treated); (5) knowledge, beliefs and behaviours regarding malaria, its prevention and treatment, and exposure to malaria-related messages.

\subsection{Variables}

\subsubsection{Outcome Variable}

The dependent variable was the use of IPTp with SP/Fansidar during pregnancy. This information was collected from women aged 15-49 years who had had a live birth in the two years prior to the interview. IPTp should be given at every antenatal visit (except in the first trimester and in doses at least one month apart) [15]. The new policy does not mention a specific number of doses, but scientific evidence has shown that three or more doses of SP for IPTp have been associated with higher average birth weight and fewer low-birth-weight infants, corresponding to a relative risk reduction of $20 \%$ for low birth weight and an absolute risk reduction of 33 per 1000 births [16]. In this study, the dependent variable had two modalities: 'At least three or more doses' and 'Less than three doses'.

\subsubsection{Independent Variables}

The selection of independent variables was based on a review of the literature, particularly the conceptual model of Chikwasha et al. [17] on predictors of IPTp uptake among pregnant women in Zimbabwe using DHS data. Their conceptual framework includes two groups of variables, namely, health-related and sociodemographic characteristics.

The independent variables included in this study were health-related characteristics such as the type of health worker consulted at the first antenatal care visit and the conduct of antenatal visits. In addition, sociodemographic characteristics such as parity, women's age, religion, household wealth quintile, education level and place of residence were included. Variables on women's KAP in relation to malaria, such as access to malaria information, knowledge of malaria symptoms, causes and prevention methods, and types of prevention methods used, were included in the analysis.

\subsection{Methods of Analysis}

Data analysis was performed using Stata 15.1. Two types of analysis were used: a bivariate analysis and a logistic regression model. The bivariate analysis of each independent variable was performed in relation to the dependent variable to obtain the impact of each factor on the outcome variable. The chi-square $(\chi 2)$ significance level was set at $\mathrm{P}<0.05$. Bivariate and multivariate logistic regressions were used to estimate crude odds ratios (OR) and adjusted odds ratios (aOR) to determine the factors associated with IPTp compliance.

\section{Results}

\subsection{Background Characteristics of the Respondents}

Table 1 shows the percentage distribution of the sample. The majority of the sample is comprised of women aged 25 29 (25.8\% in 2014 and 25.1\% in 2017), women of Muslim religion $(66.4 \%$ in 2014 and $63.1 \%$ in 2017$)$ and women with no education (79.1\% in 2014 and $75.4 \%$ in 2017). Regarding their place of residence, more than eight out of 10 women resided in rural areas in 2014 and 2017. Almost all $(97 \%$ in 2014 and $99 \%$ in 2017) had made at least one antenatal visit, and the majority (46.8\% in 2014 and $53 \%$ in 2017) had received antenatal care from a midwife. All of them appeared to be aware of the symptoms of malaria and the means to prevent the disease.

Table 1. Description of the study sample.

\begin{tabular}{|c|c|c|c|c|}
\hline \multirow{2}{*}{ Variables } & \multicolumn{2}{|l|}{2014} & \multicolumn{2}{|l|}{2017} \\
\hline & $\mathbf{n}$ & $\%$ & $\mathbf{n}$ & $\%$ \\
\hline $\mathrm{N}$ & 4824 & 100 & 4504 & 100 \\
\hline \multicolumn{5}{|l|}{ Number of IPTp doses received } \\
\hline Less than three doses & 2105 & 43.6 & 1675 & 37.2 \\
\hline At least three or more doses & 2719 & 56.4 & 2829 & 62.8 \\
\hline \multicolumn{5}{|l|}{ Age group } \\
\hline $15-19$ & 378 & 7.8 & 295 & 6.5 \\
\hline $20-24$ & 1,068 & 22.1 & 915 & 20.3 \\
\hline $25-29$ & 1,243 & 25.8 & 1,130 & 25.1 \\
\hline $30-34$ & 991 & 20.5 & 946 & 21 \\
\hline $35-39$ & 740 & 15.3 & 782 & 17.4 \\
\hline $40-44$ & 310 & 6.4 & 323 & 7.2 \\
\hline $45-49$ & 94 & 1.9 & 113 & 2.5 \\
\hline \multicolumn{5}{|l|}{ Parity } \\
\hline 1 & 810 & 16.8 & 776 & 17.2 \\
\hline 2 & 802 & 16.6 & 771 & 17.1 \\
\hline 3 & 728 & 15.1 & 696 & 15.5 \\
\hline 4 & 690 & 14.3 & 681 & 15.1 \\
\hline 5 & 558 & 11.6 & 546 & 12.1 \\
\hline 6 and over & 1,236 & 25.6 & 1,034 & 23 \\
\hline \multicolumn{5}{|l|}{ Religion } \\
\hline Muslim & 3,197 & 66.4 & 2,834 & 63.1 \\
\hline Christian & 1,216 & 25.2 & 1,386 & 30.8 \\
\hline No religion/Other & 403 & 8.4 & 274 & 6.1 \\
\hline
\end{tabular}




\begin{tabular}{|c|c|c|c|c|}
\hline \multirow{2}{*}{ Variables } & \multicolumn{2}{|l|}{2014} & \multicolumn{2}{|l|}{2017} \\
\hline & $\mathrm{n}$ & $\%$ & $\mathrm{n}$ & $\%$ \\
\hline \multicolumn{5}{|l|}{ Instruction } \\
\hline No level & 3,814 & 79.1 & 3,396 & 75.4 \\
\hline Primary & 620 & 12.9 & 610 & 13.5 \\
\hline Secondary and above & 390 & 8.1 & 498 & 11.1 \\
\hline \multicolumn{5}{|l|}{ Wealth index combined } \\
\hline Poorest & 1,016 & 21.1 & 904 & 20.1 \\
\hline Poorer & 1,066 & 22.1 & 983 & 21.8 \\
\hline Middle & 1,130 & 23.4 & 937 & 20.8 \\
\hline Richer & 1,049 & 21.7 & 918 & 20.4 \\
\hline Richest & 563 & 11.7 & 762 & 16.9 \\
\hline \multicolumn{5}{|l|}{ Place of residence } \\
\hline Urban & 774 & 16 & 738 & 16.4 \\
\hline Rural & 4,050 & 84 & 3,766 & 83.6 \\
\hline \multicolumn{5}{|l|}{ Administrative region } \\
\hline Boucle du Mouhoun & 403 & 8.4 & 369 & 8.2 \\
\hline Waterfalls & 390 & 8.1 & 427 & 9.5 \\
\hline Centre & 278 & 5.8 & 230 & 5.1 \\
\hline Central East & 437 & 9.1 & 355 & 7.9 \\
\hline North Central & 411 & 8.5 & 423 & 9.4 \\
\hline Central West & 377 & 7.8 & 338 & 7.5 \\
\hline South Central & 334 & 6.9 & 250 & 5.6 \\
\hline East & 335 & 6.9 & 435 & 9.7 \\
\hline High-Basins & 319 & 6.6 & 390 & 8.7 \\
\hline North & 366 & 7.6 & 384 & 8.5 \\
\hline Central Plateau & 403 & 8.4 & 373 & 8.3 \\
\hline Sahel & 441 & 9.1 & 209 & 4.6 \\
\hline South West & 330 & 6.8 & 321 & 7.1 \\
\hline \multicolumn{5}{|l|}{ At least one prenatal visit } \\
\hline No & 151 & 3.1 & 35 & 0.8 \\
\hline Yes & 4,665 & 96.9 & 4,466 & 99.2 \\
\hline \multicolumn{5}{|c|}{ Access to information on malaria } \\
\hline No & 2,626 & 54.6 & 1,783 & 39.6 \\
\hline Yes & 2,184 & 45.4 & 2,720 & 60.4 \\
\hline \multicolumn{5}{|c|}{ Knowledge of malaria symptoms } \\
\hline No & 148 & 3.1 & 151 & 3.4 \\
\hline Yes & 4,675 & 96.9 & 4,335 & 96.6 \\
\hline \multicolumn{5}{|c|}{ Knowledge of how to prevent malaria } \\
\hline Use of mosquito nets & 2,090 & 46.9 & 1,966 & 46.4 \\
\hline Chemoprevention & 291 & 6.5 & 144 & 3.4 \\
\hline Use of insecticide & 245 & 5.5 & 114 & 2.7 \\
\hline Other & 1,829 & 41.1 & 2,011 & 47.5 \\
\hline \multicolumn{5}{|l|}{ Means of prevention used } \\
\hline Use of mosquito nets & 2,279 & 50.9 & 839 & 19.9 \\
\hline Chemoprevention & 222 & 5 & 32 & 0.8 \\
\hline Use of insecticide & 226 & 5 & 373 & 8.8 \\
\hline Other & 1,752 & 39.1 & 2,982 & 70.6 \\
\hline \multicolumn{5}{|c|}{ Knowledge of causes of malaria } \\
\hline No & 711 & 14.7 & 503 & 11.2 \\
\hline Yes & 4,113 & 85.3 & 4,000 & 88.8 \\
\hline \multicolumn{5}{|l|}{ Antenatal care provider } \\
\hline Doctor & 61 & 1.3 & 58 & 1.3 \\
\hline Nurse & 454 & 9.4 & 1,034 & 23 \\
\hline Midwife & 2,256 & 46.8 & 2,429 & 53.9 \\
\hline Auxiliary birth attendant & 1,846 & 38.3 & 838 & 18.6 \\
\hline Skilled birth attendant & 47 & 1 & 90 & 2 \\
\hline Traditional & 16 & 0.3 & 29 & 0.6 \\
\hline Other & 144 & 3 & 26 & 0.6 \\
\hline
\end{tabular}

\subsection{Bivariate Associations of Independent Variables with the Number of IPTp Doses Received}

Table 2 shows the distribution of women according to potential associated factors and IPTp adherence during pregnancy for the 2014 and 2017 surveys. The distribution according to household standard of living showed that the proportion of IPTp compliance was highest among women living in middle-income households (49.02\%) and the lowest among those living in the richest households, where only $27.66 \%$ took the recommended number of three or more doses $(\mathrm{P}<0.001)$ in 2014. The same trend was observed in 2017. IPTp adherence varied significantly by residence and 
region of residence in 2014, whereas in 2017, residence was not significant. In fact, it was significantly higher in rural areas $(47.16 \%)$ than in urban areas in the 2014 survey. Regarding the regions, it varied from a minimum of $14.94 \%$ in the Hauts-Bassins region to a maximum of $64.83 \%$ in the Centre-East $(\mathrm{P}<0.001)$. There were significant variations by region in the reception of at least three doses of IPTp among pregnant women. Women who had made at least one prenatal visit during pregnancy and those who had consulted a doctor during pregnancy were proportionally more likely to have received at least three doses of IPTp during pregnancy in both the 2014 and 2017 surveys. Regarding women with access to malaria information, the results of the 2014 data show that they are more likely than those without access to information to have had at least three doses of IPTp during pregnancy.

Table 2. Bivariate associations of independent variables with the number of IPTp doses received.

\begin{tabular}{|c|c|c|c|c|c|}
\hline \multirow{3}{*}{ Variables } & \multicolumn{5}{|c|}{ Number of IPTp doses received } \\
\hline & \multicolumn{5}{|c|}{2014} \\
\hline & Less than three doses & At least three doses & Total & $\mathbf{n}$ & P value \\
\hline \multicolumn{6}{|l|}{ Age group } \\
\hline $15-19$ & 41.8 & 58.2 & 100 & 378 & \multirow{7}{*}{0.782} \\
\hline $20-24$ & 42.3 & 57.7 & 100 & 1,068 & \\
\hline $25-29$ & 44 & 56 & 100 & 1,243 & \\
\hline $30-34$ & 44.4 & 55.6 & 100 & 991 & \\
\hline $35-39$ & 45.4 & 54.6 & 100 & 740 & \\
\hline $40-44$ & 43.5 & 56.5 & 100 & 310 & \\
\hline $45-49$ & 39.4 & 60.6 & 100 & 94 & \\
\hline \multicolumn{6}{|l|}{ Parity } \\
\hline 1 & 41.2 & 58.8 & 100 & 810 & \multirow{6}{*}{0.448} \\
\hline 2 & 43.3 & 56.7 & 100 & 802 & \\
\hline 3 & 42 & 58 & 100 & 728 & \\
\hline 4 & 45.5 & 54.5 & 100 & 690 & \\
\hline 5 & 45.2 & 54.8 & 100 & 558 & \\
\hline 6 and over & 44.7 & 55.3 & 100 & 1,236 & \\
\hline \multicolumn{6}{|l|}{ Religion } \\
\hline Muslim & 45.4 & 54.6 & 100 & 3,197 & \multirow{3}{*}{0.003} \\
\hline Christian & 40.5 & 59.5 & 100 & 1,216 & \\
\hline No religion/ Other & 39.5 & 60.5 & 100 & 403 & \\
\hline \multicolumn{6}{|l|}{ Women's education } \\
\hline Not educated & 43.8 & 56.2 & 100 & 3,814 & \multirow{3}{*}{0.842} \\
\hline Primary & 43.4 & 56.6 & 100 & 620 & \\
\hline Secondary and above & 42.3 & 57.7 & 100 & 390 & \\
\hline \multicolumn{6}{|l|}{ Wealth index combined } \\
\hline Poorest & 45.5 & 54.5 & 100 & 1,016 & \multirow{5}{*}{0.001} \\
\hline Poorer & 46.1 & 53.9 & 100 & 1,066 & \\
\hline Middle & 44.2 & 55.8 & 100 & 1,130 & \\
\hline Richer & 43.5 & 56.5 & 100 & 1,049 & \\
\hline Richest & 35 & 65 & 100 & 563 & \\
\hline \multicolumn{6}{|l|}{ Place of residence } \\
\hline Urban & 38.5 & 61.5 & 100 & 774 & \multirow{2}{*}{0.002} \\
\hline Rural & 44.6 & 55.4 & 100 & 4,050 & \\
\hline \multicolumn{6}{|l|}{ Region } \\
\hline Boucle du Mouhoun & 40.7 & 59.3 & 100 & 403 & \multirow{13}{*}{0.001} \\
\hline Waterfalls & 53.6 & 46.4 & 100 & 390 & \\
\hline Centre & 31.7 & 68.3 & 100 & 278 & \\
\hline Central East & 36.8 & 63.2 & 100 & 437 & \\
\hline North Central & 55.5 & 44.5 & 100 & 411 & \\
\hline Central West & 60.2 & 39.8 & 100 & 377 & \\
\hline South Central & 48.2 & 51.8 & 100 & 334 & \\
\hline East & 19.7 & 80.3 & 100 & 335 & \\
\hline High-Basins & 19.7 & 80.3 & 100 & 319 & \\
\hline North & 55.5 & 44.5 & 100 & 366 & \\
\hline Central Plateau & 42.2 & 57.8 & 100 & 403 & \\
\hline Sahel & 50.8 & 49.2 & 100 & 441 & \\
\hline South West & 42.7 & 57.3 & 100 & 330 & \\
\hline \multicolumn{6}{|c|}{ At least one prenatal visit } \\
\hline No & 19.2 & 80.8 & 100 & 151 & \\
\hline Yes & 44.4 & 55.6 & 100 & 4,665 & 0.001 \\
\hline Access to information & & & & & \\
\hline No & 42.1 & 57.9 & 100 & 2,626 & \\
\hline Yes & 45.5 & 54.5 & 100 & 2,184 & 0.017 \\
\hline Knowledge of malaria & & & & & \\
\hline
\end{tabular}




\begin{tabular}{|c|c|c|c|c|c|}
\hline \multirow{3}{*}{ Variables } & \multicolumn{5}{|c|}{ Number of IPTp doses received } \\
\hline & \multicolumn{5}{|c|}{2014} \\
\hline & Less than three doses & At least three doses & Total & n & Pvalue \\
\hline No & 39.9 & 60.1 & 100 & 148 & \multirow{3}{*}{0.349} \\
\hline Yes & 43.7 & 56.3 & 100 & 4,675 & \\
\hline \multicolumn{5}{|c|}{ Knowledge of how to prevent malaria } & \\
\hline Use of mosquito nets & 43.1 & 56.9 & 100 & 2,090 & \multirow{4}{*}{0.105} \\
\hline Chemo prevention & 40.5 & 59.5 & 100 & 291 & \\
\hline Use of insecticide & 42.9 & 57.1 & 100 & 245 & \\
\hline Other & 46.3 & 53.7 & 100 & 1,829 & \\
\hline \multicolumn{6}{|l|}{ Means of prevention used } \\
\hline Use of mosquito nets & 43.2 & 56.8 & 100 & 2,279 & \multirow{4}{*}{0.121} \\
\hline Chemoprevention & 39.6 & 60.4 & 100 & 222 & \\
\hline Use of insecticide & 41.6 & 58.4 & 100 & 226 & \\
\hline Other & 46.1 & 53.9 & 100 & 1,752 & \\
\hline \multicolumn{6}{|c|}{ Knowledge of causes of malaria } \\
\hline No & 42.2 & 57.8 & 100 & 711 & \multirow{3}{*}{0.401} \\
\hline Yes & 43.9 & 56.1 & 100 & 4,113 & \\
\hline \multicolumn{5}{|l|}{ Antenatal care provider } & \\
\hline Doctor & 31.1 & 68.9 & 100 & 61 & \multirow{8}{*}{0.001} \\
\hline Nurse & 50 & 50 & 100 & 454 & \\
\hline Midwife & 42.9 & 57.1 & 100 & 2,256 & \\
\hline Auxiliary birth attendant & 44.9 & 55.1 & 100 & 1,846 & \\
\hline Skilled birth attendant & 61.7 & 38.3 & 100 & 47 & \\
\hline Traditional & 18.8 & 81.2 & 100 & 16 & \\
\hline Other & 20.8 & 79.2 & 100 & 144 & \\
\hline $\mathrm{N}$ & 43.6 & 56.4 & 100 & 4,824 & \\
\hline
\end{tabular}

Table 2. Continued.

\begin{tabular}{|c|c|c|c|c|c|}
\hline \multirow{3}{*}{ Variables } & \multicolumn{5}{|c|}{ Number of IPTp doses received } \\
\hline & \multicolumn{5}{|c|}{2017} \\
\hline & Less than three doses & At least three doses & Total & $\mathbf{n}$ & Pvalue \\
\hline \multicolumn{6}{|l|}{ Age group } \\
\hline $15-19$ & 36.3 & 63.7 & 100 & 295 & \multirow{7}{*}{0.143} \\
\hline $20-24$ & 38.6 & 61.4 & 100 & 915 & \\
\hline $25-29$ & 38.1 & 61.9 & 100 & 1,130 & \\
\hline $30-34$ & 38.4 & 61.6 & 100 & 946 & \\
\hline $35-39$ & 35.5 & 64.5 & 100 & 782 & \\
\hline $40-44$ & 30.3 & 69.7 & 100 & 323 & \\
\hline $45-49$ & 39.8 & 60.2 & 100 & 113 & \\
\hline \multicolumn{6}{|l|}{ Parity } \\
\hline 1 & 38.8 & 61.2 & 100 & 776 & \multirow{6}{*}{0.189} \\
\hline 2 & 38.8 & 61.2 & 100 & 771 & \\
\hline 3 & 35.9 & 64.1 & 100 & 696 & \\
\hline 4 & 39.8 & 60.2 & 100 & 681 & \\
\hline 5 & 35.9 & 64.1 & 100 & 546 & \\
\hline 6 and over & 34.6 & 65.4 & 100 & 1,034 & \\
\hline \multicolumn{6}{|l|}{ Religion } \\
\hline Muslim & 38.4 & 61.6 & 100 & 2,834 & \multirow{3}{*}{0.014} \\
\hline Christian & 36.1 & 63.9 & 100 & 1,386 & \\
\hline No religion/ Other & 29.9 & 70.1 & 100 & 274 & \\
\hline \multicolumn{6}{|l|}{ Women's education } \\
\hline Not educated & 36.8 & 63.2 & 100 & 3,396 & \multirow{3}{*}{0.393} \\
\hline Primary & 39.7 & 60.3 & 100 & 610 & \\
\hline Secondary and above & 36.9 & 63.1 & 100 & 498 & \\
\hline \multicolumn{6}{|l|}{ Wealth index combined } \\
\hline Poorest & 36.9 & 63.1 & 100 & 904 & \multirow{5}{*}{0.042} \\
\hline Poorer & 36.4 & 63.6 & 100 & 983 & \\
\hline Middle & 36.3 & 63.7 & 100 & 937 & \\
\hline Richer & 41.4 & 58.6 & 100 & 918 & \\
\hline Richest & 34.5 & 65.5 & 100 & 762 & \\
\hline \multicolumn{6}{|l|}{ Place of residence } \\
\hline Urban & 36.6 & 63.4 & 100 & 738 & \multirow{3}{*}{0.711} \\
\hline Rural & 37.3 & 62.7 & 100 & 3,766 & \\
\hline \multicolumn{5}{|l|}{ Region } & \\
\hline Boucle du Mouhoun & 22 & 78 & 100 & 369 & \multirow{2}{*}{0.001} \\
\hline Waterfalls & 56.9 & 43.1 & 100 & 427 & \\
\hline
\end{tabular}




\begin{tabular}{|c|c|c|c|c|c|}
\hline \multirow{3}{*}{ Variables } & \multicolumn{5}{|c|}{ Number of IPTp doses received } \\
\hline & \multicolumn{5}{|c|}{2017} \\
\hline & Less than three doses & At least three doses & Total & $\mathbf{n}$ & P value \\
\hline Centre & 35.7 & 64.3 & 100 & 230 & \\
\hline Central East & 42.3 & 57.7 & 100 & 355 & \\
\hline North Central & 28.8 & 71.2 & 100 & 423 & \\
\hline Central West & 44.4 & 55.6 & 100 & 338 & \\
\hline South Central & 40.8 & 59.2 & 100 & 250 & \\
\hline East & 37.2 & 62.8 & 100 & 435 & \\
\hline High-Basins & 34.6 & 65.4 & 100 & 390 & \\
\hline North & 39.8 & 60.2 & 100 & 384 & \\
\hline Central Plateau & 32.2 & 67.8 & 100 & 373 & \\
\hline Sahel & 48.3 & 51.7 & 100 & 209 & \\
\hline South West & 23.1 & 76.9 & 100 & 321 & \\
\hline \multicolumn{6}{|l|}{ At least one prenatal visit } \\
\hline No & 11.4 & 88.6 & 100 & 35 & \multirow{2}{*}{0.002} \\
\hline Yes & 37.4 & 62.6 & 100 & 4,466 & \\
\hline \multicolumn{6}{|c|}{ Access to information on malaria } \\
\hline No & 38.4 & 61.6 & 100 & 1,783 & \multirow{2}{*}{0.190} \\
\hline Yes & 36.4 & 63.6 & 100 & 2,720 & \\
\hline \multicolumn{6}{|c|}{ Knowledge of malaria symptoms } \\
\hline No & 40.4 & 59.6 & 100 & 151 & \multirow{2}{*}{0.412} \\
\hline Yes & 37.1 & 62.9 & 100 & 4,335 & \\
\hline \multicolumn{6}{|c|}{ Knowledge of how to prevent malaria } \\
\hline Use of mosquito nets & 36.9 & 63.1 & 100 & 1,966 & \multirow{4}{*}{0373} \\
\hline Chemo prevention & 41.7 & 58.3 & 100 & 144 & \\
\hline Use of insecticide & 31.6 & 68.4 & 100 & 114 & \\
\hline Other & 37.8 & 62.2 & 100 & 2,011 & \\
\hline \multicolumn{6}{|l|}{ Means of prevention used } \\
\hline Use of mosquito nets & 38.3 & 61.7 & 100 & 839 & \multirow{4}{*}{0.435} \\
\hline Chemoprevention & 28.1 & 71.9 & 100 & 32 & \\
\hline Use of insecticide & 39.4 & 60.6 & 100 & 373 & \\
\hline Other & 36.6 & 63.4 & 100 & 2,982 & \\
\hline \multicolumn{6}{|c|}{ Knowledge of causes of malaria } \\
\hline No & 36.6 & 63.4 & 100 & 503 & \multirow{2}{*}{0.770} \\
\hline Yes & 37.2 & 62.7 & 100 & 4,000 & \\
\hline \multicolumn{6}{|l|}{ Antenatal care provider } \\
\hline Doctor & 31 & 69 & 100 & 58 & \multirow{8}{*}{0.002} \\
\hline Nurse & 39.7 & 60.3 & 100 & 1,034 & \\
\hline Midwife & 35.9 & 64.1 & 100 & 2,429 & \\
\hline Auxiliary birth attendant & 40.1 & 59.9 & 100 & 838 & \\
\hline Skilled birth attendant & 34.4 & 65.6 & 100 & 90 & \\
\hline Traditional & 13.8 & 86.2 & 100 & 29 & \\
\hline Other & 15.4 & 84.6 & 100 & 26 & \\
\hline $\mathrm{N}$ & 37.2 & 62.8 & 100 & 4,504 & \\
\hline
\end{tabular}

\subsection{Factors Associated with Receiving at Least Three Doses of IPTp During Their Last Pregnancy}

Regarding the factors associated with receiving at least three doses of IPTp during the last pregnancy (Table 3), it was found that religion, education level, household standard of living, region of residence and type of caregiver were the significant variables for the 2014 survey, while in the 2017 survey, the significant variables were household standard of living, region of residence and access to malaria information.

For the 2014 survey, with regard to religion, it was found that Christian women $(\mathrm{aOR}=1.18 ; 95 \% \mathrm{CI}: 1.01-1.38)$ were more likely to have three or more doses compared to Muslim women. In relation to women's education level, it was found that women with secondary school or higher qualifications were $25 \%$ less likely (aOR $=0.741$; 95\% CI: $0.568-0.965)$ than women with no education to have three or more doses of IPTp during pregnancy. With regard to household standard of living, women from very wealthy households ( $\mathrm{aOR}=1.678 ; 95 \% \mathrm{CI}$ : $1.19-2.356)$, wealthy households $(\mathrm{aOR}=1.433 ; 95 \% \mathrm{CI}: 1.55$ $1.778)$ or middle-income households $(\mathrm{aOR}=1.377 ; 95 \% \mathrm{CI}$ : 1.119-1.696) had a higher probability of having three or more doses of IPTp during their pregnancies compared to women from poor households. Compared to the Boucle du Mouhoun region, women in the Eastern region $(\mathrm{aOR}=2.658 ; 95 \% \mathrm{CI}$ : 1.807-3.910) and the Hauts-Bassins region $(\mathrm{aOR}=2.491 ; 95 \%$ CI: 1.677-3.699) were more likely to receive three or more doses of IPTp during their pregnancy. However, for women in the Cascades $(\mathrm{aOR}=0.564 ; 95 \%$ CI: $0.410-0.774)$, North Central $\quad(\mathrm{aOR}=0.581 ; 95 \%$ CI: $0.429-0.786)$, West Central $(\mathrm{aOR}=0.387 ; 95 \% \quad \mathrm{CI}: \quad 0.283-0.528)$ and the North ( $\mathrm{aOR}=0.489 ; 95 \%$ CI: $0.352-0.679)$, the probability of receiving three or more doses of IPTp during pregnancy was low compared to women in Boucle du Mouhoun. Regarding the antenatal care provider variable, women who had had antenatal visits with a nurse $(\mathrm{aOR}=0.437 ; 95 \%$ CI: 0.237 - 
$0.805)$ or with a skilled birth attendant $(\mathrm{aOR}=0.257 ; 95 \% \mathrm{CI}$ : $0.107-0.617$ ) were less likely to have three or more doses compared to women who had had antenatal visits with a doctor

Other characteristics such as age, parity, area of residence (urban vs. rural) and knowledge of malaria signs were not associated with receiving three or more doses of IPTp during pregnancy.

In the 2017 survey, only the variables region of residence and access to malaria information were associated with receiving at least three or more doses of IPTp during pregnancy. Compared to the region, except for the SouthWest region, women in the other regions were less likely to receive at least three or more doses of IPTp during pregnancy, compared to women in the Boucle du Mouhoun region. Regarding access to malaria information, women who had access $(\mathrm{aOR}=1.162$; 95\% CI: $1.006-1.342)$ were more likely to have at least three or more doses of IPTp during pregnancy compared to women who did not have access to malaria information.

Table 3. Factors associated with receiving at least three doses of IPTp during their last pregnancy from logistic regression.

\begin{tabular}{|c|c|c|c|c|}
\hline \multirow{2}{*}{ Variables } & \multicolumn{2}{|l|}{2014 MIS } & \multicolumn{2}{|l|}{2017 MIS } \\
\hline & Adjusted odds ratio (aOR) & 95\% Confidence interval & Adjusted odds ratio (aOR) & 95\% Confidence interval \\
\hline \multicolumn{5}{|l|}{ Age group } \\
\hline \multicolumn{5}{|l|}{$15-19$} \\
\hline $20-24$ & 0.996 & {$[0.753,1.316]$} & 0.853 & {$[0.620,1.174]$} \\
\hline $25-29$ & 0.908 & {$[0.665,1.239]$} & 0.797 & {$[0.561,1.134]$} \\
\hline $30-34$ & 0.829 & {$[0.590,1.164]$} & 0.706 & {$[0.479,1.040]$} \\
\hline $35-39$ & 0.832 & {$[0.573,1.206]$} & 0.813 & {$[0.539,1.226]$} \\
\hline $40-44$ & 0.82 & {$[0.533,1.264]$} & 1.019 & {$[0.635,1.634]$} \\
\hline $45-49$ & 1.149 & {$[0.632,2.090]$} & 0.61 & {$[0.344,1.080]$} \\
\hline \multicolumn{5}{|l|}{ Parity } \\
\hline \multicolumn{5}{|l|}{1} \\
\hline 2 & 0.886 & {$[0.701,1.121]$} & 1.085 & {$[0.845,1.392]$} \\
\hline 3 & 1.012 & {$[0.776,1.319]$} & 1.204 & {$[0.904,1.603]$} \\
\hline 4 & 0.902 & {$[0.678,1.202]$} & 1.085 & {$[0.795,1.481]$} \\
\hline 5 & 0.966 & {$[0.706,1.323]$} & 1.286 & {$[0.910,1.817]$} \\
\hline 6 and over & 0.948 & {$[0.692,1.298]$} & 1.242 & {$[0.881,1.752]$} \\
\hline \multicolumn{5}{|l|}{ Religion } \\
\hline \multicolumn{5}{|l|}{ Muslim } \\
\hline Christian & $1.185 * *$ & {$[1.010,1.389]$} & 0.932 & {$[0.796,1.092]$} \\
\hline No religion/Other & 1.214 & {$[0.931,1.583]$} & 1.01 & {$[0.715,1.426]$} \\
\hline \multicolumn{5}{|l|}{ Education } \\
\hline \multicolumn{5}{|l|}{ No } \\
\hline Primary & 0.849 & {$[0.699,1.032]$} & 0.869 & {$[0.712,1.061]$} \\
\hline Secondary and above & $0.741 * *$ & {$[0.568,0.965]$} & 0.914 & {$[0.717,1.167]$} \\
\hline \multicolumn{5}{|l|}{ Wealth index } \\
\hline \multicolumn{5}{|l|}{ Poorest } \\
\hline Poorer & 1.182 & {$[0.963,1.452]$} & 1.12 & {$[0.904,1.389]$} \\
\hline Middle & $1.377 * * *$ & {$[1.119,1.696]$} & 1.106 & {$[0.889,1.377]$} \\
\hline Richer & $1.433 * * *$ & {$[1.155,1.778]$} & 0.927 & {$[0.744,1.155]$} \\
\hline Richest & $1.678 * * *$ & {$[1.195,2.356]$} & $1.343 *$ & {$[1.007,1.791]$} \\
\hline \multicolumn{5}{|l|}{ Residence } \\
\hline \multicolumn{5}{|l|}{ Urban } \\
\hline Rural & 1.034 & {$[0.817,1.309]$} & 0.975 & {$[0.767,1.239]$} \\
\hline \multicolumn{5}{|l|}{ Region } \\
\hline \multicolumn{5}{|l|}{ Boucle du Mouhoun } \\
\hline Waterfalls & $0.564 * * *$ & {$[0.410,0.774]$} & $0.184 * * *$ & {$[0.131,0.259]$} \\
\hline Centre & 1.196 & {$[0.817,1.752]$} & $0.437 * * *$ & {$[0.282,0.677]$} \\
\hline Central East & 1.183 & {$[0.867,1.615]$} & $0.333 * * *$ & {$[0.232,0.479]$} \\
\hline North Central & $0.581 * * *$ & {$[0.429,0.786]$} & $0.615 * * *$ & {$[0.430,0.878]$} \\
\hline Central West & $0.387 * *$ & {$[0.283,0.528]$} & $0.333 * * *$ & {$[0.228,0.485]$} \\
\hline South Central & 0.767 & {$[0.552,1.065]$} & $0.381 * * *$ & {$[0.256,0.566]$} \\
\hline East & $2.658 * * *$ & {$[1.807,3.910]$} & $0.467 * * *$ & {$[0.319,0.683]$} \\
\hline High-Basins & $2.491 * * *$ & {$[1.677,3.699]$} & $0.451 * * *$ & {$[0.317,0.643]$} \\
\hline North & $0.489 * * *$ & {$[0.352,0.679]$} & $0.365 * * *$ & {$[0.252,0.529]$} \\
\hline Central Plateau & 0.859 & {$[0.620,1.189]$} & $0.56^{* * *}$ & {$[0.386,0.814]$} \\
\hline Sahel & 0.783 & {$[0.555,1.105]$} & $0.219 * * *$ & {$[0.138,0.349]$} \\
\hline South West & 0.845 & {$[0.600,1.190]$} & 0.918 & {$[0.594,1.419]$} \\
\hline \multicolumn{5}{|c|}{ Access to information on malaria } \\
\hline \multicolumn{5}{|c|}{ No } \\
\hline Yes & 0.957 & {$[0.837,1.096]$} & $1.162 * *$ & {$[1.006,1.342]$} \\
\hline \multicolumn{5}{|c|}{ Knowledge of malaria symptoms } \\
\hline No & & & & \\
\hline Yes & 1.057 & {$[0.668,1.673]$} & 1.148 & {$[0.725,1.820]$} \\
\hline
\end{tabular}




\begin{tabular}{|c|c|c|c|c|}
\hline \multirow{2}{*}{ Variables } & \multicolumn{2}{|l|}{2014 MIS } & \multicolumn{2}{|l|}{2017 MIS } \\
\hline & Adjusted odds ratio (aOR) & 95\% Confidence interval & Adjusted odds ratio (aOR) & 95\% Confidence interval \\
\hline \multicolumn{5}{|c|}{ Knowledge of how to prevent malaria } \\
\hline \multicolumn{5}{|c|}{ Use of mosquito nets } \\
\hline Chemoprevention & 1.102 & {$[0.773,1.570]$} & 0.904 & {$[0.621,1.314]$} \\
\hline Use of insecticide & 0.98 & {$[0.698,1.377]$} & 1.311 & {$[0.852,2.018]$} \\
\hline Other & 0.961 & {$[0.799,1.157]$} & 0.924 & {$[0.795,1.073]$} \\
\hline \multicolumn{5}{|l|}{ Means of prevention used } \\
\hline \multicolumn{5}{|l|}{ Use of mosquito nets } \\
\hline Chemoprevention & 1.138 & {$[0.764,1.695]$} & 2 & {$[0.866,4.616]$} \\
\hline Use of insecticide & 1.036 & {$[0.728,1.474]$} & 1.111 & {$[0.846,1.459]$} \\
\hline Other & 0.924 & {$[0.772,1.106]$} & 1.145 & {$[0.953,1.374]$} \\
\hline \multicolumn{5}{|c|}{ Knowledge of causes of malaria } \\
\hline \multicolumn{5}{|c|}{ No } \\
\hline Yes & 0.963 & {$[0.768,1.208]$} & 0.93 & {$[0.714,1.211]$} \\
\hline \multicolumn{5}{|l|}{ Antenatal care provider } \\
\hline Doctor & & & & \\
\hline Nurse & $0.437 * * *$ & {$[0.237,0.805]$} & 0.716 & {$[0.391,1.312]$} \\
\hline Midwife & 0.596 & {$[0.333,1.066]$} & 0.843 & {$[0.464,1.532]$} \\
\hline Auxiliary birth attendant & 0.583 & {$[0.322,1.056]$} & 0.684 & {$[0.370,1.266]$} \\
\hline Skilled birth attendant & $0.257 * * *$ & {$[0.107,0.617]$} & 0.534 & {$[0.246,1.163]$} \\
\hline Traditional/Other & 1.252 & {$[0.305,5.134]$} & 2.815 & {$[0.722,10.98]$} \\
\hline Constant & 2.294 & {$[0.972,5.41]$} & 4.296 & {$[1.688,10.934]$} \\
\hline
\end{tabular}

\section{Discussion}

The national guidelines for the management of malaria in health facilities in Burkina Faso in 2014 and 2017 stated that IPTp, which starts in the second trimester after the onset of active foetal movements, consists of three tablets of SP in one oral dose from the second trimester of pregnancy until delivery, with a minimum interval of one month between doses. At least three doses of SP have been recommended during pregnancy in Burkina Faso since March 2014 [18].

The objective of this study was to identify the different factors that may influence the use of IPTp by pregnant women in Burkina Faso. The results show that the determinants of IPTp use were different between 2014 and 2017.

In Burkina Faso, 56\% and $63 \%$ of pregnant women had received at least three or more doses of IPTp during pregnancy in 2014 and 2017, respectively. Although progress has been made, it is far from the target, of $80 \%$ of eligible pregnant women receiving at least three doses of IPTp during pregnancy, set by the Ministry of Health and WHO [19, 20]. Regarding factors associated with receiving three or more doses, religion, education level, household standard of living, region of residence and type of caregiver were the significant variables for the 2014 survey, while in the 2017 survey, the significant variables were household standard of living, region of residence and access to malaria information. In the 2014 survey, Muslim women, women from low-income households and women having consulted a health worker other than a doctor reported low use of IPTp. In a study in Tanzania, a significant relationship was found between IPTp uptake and certain sociodemographic characteristics of women, such as education level, age, occupation, wealth, gender and region of residence [5]. Unexpectedly, the results of the study show that women with a secondary education or higher qualifications were less likely to have received three or more doses than women with no education. A similar result was found in the study by Yaya et al. [21]; education was positively associated with receiving at least one dose of IPTp in Kenya [22, 23], Malawi [24] and Uganda [25]. Hill et al. [26] found that women with higher levels of education were more likely to receive IPTp than women with less or no education, as were wealthier women.

In the 2017 survey, women from wealthy households and women who had access to information on malaria were more likely to receive at least three doses of IPTp during pregnancy. Lack of knowledge of malaria has been found in several studies $[13,26,27]$ to be an important determinant of receiving IPTp doses during pregnancy.

Only two variables (region of residence and household standard of living) were found to be significantly associated with receiving at least one dose of IPTp during pregnancy. This result seems to indicate regional disparities in IPTp administration, lack of implementation of clear policies/guidelines on IPTp administration, regional variation in health-care worker behaviour in dispensing IPTp and insufficient awareness of women during antenatal visits to receive IPTp doses. Hill et al. [26] found that the lack of clear policies and guidelines as well as inadequate training, supervision and quality assurance at the health facility level were responsible for many of the barriers to effective implementation of IPTp.

Strengths and limitations of the study

The main strength of this study is the use of a nationally representative dataset that used a multistage sampling technique to select respondents, making it possible to generalise the results to the national level. The main limitation is that it was based on self-reporting and therefore is susceptible to recall bias. This analysis was also limited to the variables available in the dataset. Mix of quantitative and qualitative methodology is recommended for further studies with women during prenatal consultations to identify factors that influence the uptake of IPTp. 


\section{Conclusion}

Malaria during pregnancy often leads to maternal anaemia and low birth weight in cases of stable endemic transmission. In Burkina Faso, malaria is endemic, and women and children are the most vulnerable. The study results show that $56 \%$ and $63 \%$ of pregnant women had received at least three or more doses of IPTp during pregnancy in 2014 and 2017, respectively. Regarding factors associated with receiving three or more doses, religion, education level, household standard of living, region of residence and type of provider were the significant variables in the 2014 survey, while in the 2017 survey, the significant variables were household standard of living, region of residence and access to malaria information. Plausible interventions should be made to increase reception of at least three doses of IPTp during pregnancy by explaining to women the benefits of SP to help effectively control malaria and thus increase foetal and infant survival at birth. Interventions could target women from disadvantaged social backgrounds through awareness-raising on the importance of IPTp during pregnancy.

\section{Conflict of Interests}

All the authors do not have any possible conflicts of interest.

\section{Availability of Data and Materials}

The datasets used and/or analysed during the current study are freely available from http://dhsprogram.com/data/availabledatasets.cfm upon request.

\section{References}

[1] Desai M, Ter Kuile FO, Nosten F, McGready R, Asamoa K, Brabin B, et al. Epidemiology and burden of malaria in pregnancy. Lancet Infect Dis 2007; 7: 93-104.

[2] Amoran OE, Ariba AA, Iyaniwura CA. Determinants of intermittent preventive treatment of malaria during pregnancy (IPTp) utilization in a rural town in Western Nigeria. Reprod Health 2012; 9: 1-8. https://doi.org/10.1186/1742-4755-9-12.

[3] Guyatt HL, Snow RW. Impact of Malaria during Pregnancy on Low Birth Weight in Sub-Saharan Africa. Clin Microbiol Rev 2004; 17: 760-9. https://doi.org/10.1128/CMR.17.4.

[4] WHO. Programme mondial de lutte antipaludique : Recommandation de politique générale de l'OMS: Chimioprévention du paludisme saisonnier pour lutter contre le paludisme à Plasmodium falciparum en zone de forte transmission saisonnière dans la sous- région du S 2012; 2011: $1-4$.

[5] Kibusi SM, Kimunai E, Hines CS. Predictors for uptake of intermittent preventive treatment of malaria in pregnancy (IPTp) in Tanzania. BMC Public Health 2015; 15: 1-8. https://doi.org/10.1186/s12889-015-1905-0.

[6] Garner P, Gulmezoglu A. Drugs for preventing malariarelated illness in pregnant women and death in the newborn. Cochrane Database Syst Rev 2002. https://doi.org/10.1002/14651858.cd000169.

[7] Agboghoroma CO. Current management and prevention of malaria in pregnancy: a review. West Afr J Med 2014; 33: 91-9.

[8] Mcclure EM, Goldenberg RL, Dent AE, Meshnick SR. A systematic review of the impact of malaria prevention in pregnancy on low birth weight and maternal anemia. Int $\mathrm{J}$ Gynecol Obstet 2013; 121: 103-9. https://doi.org/10.1016/j.ijgo.2012.12.014.

[9] World Health Organization. Global technical strategy for malaria 2016-2030. World Health Organization; 2015.

[10] Ministere de la Santé du Burkina Faso. Etat de Santé la population du Burkina Faso. 2020.

[11] Institut National de la Statistique et de la Démographie (INSD) et ICF International. Enquete sur les Indicateurs du Paludisme (EIPBF) au Burkina Faso 20142015.

[12] Institut National de la Statistique et de la Démographie (INSD) Programme d'Appui au Développement Sanitaire (PADS) Programme National de Lutte contre le Paludisme (PNLP) et ICF. Enquête sur les indicateurs du paludisme au Burkina Faso, 2017-2018 2018.

[13] Pell C, Straus L, Andrew EVW, Meñaca A, Pool R. Social and cultural factors affecting uptake of interventions for malaria in pregnancy in Africa: A systematic review of the qualitative research. PLoS One 2011; 6 . https://doi.org/10.1371/journal.pone.0022452.

[14] Ndyomugyenyi R, Katamanywa J. Intermittent preventive treatment of malaria in pregnancy (IPTp): Do frequent antenatal care visits ensure access and compliance to IPTp in Ugandan rural communities? Trans R Soc Trop Med Hyg 2010; 104: 536-40. https://doi.org/10.1016/j.trstmh.2010.02.003.

[15] WHO. WHO policy brief for the Implementation of Intermittent Preventive Treatment of Malaria in Pregnancy Using Sulfadoxine-Pyrimethamine (IPTp-SP). WHO Press 2014: 1-13. https://doi.org/WHO/HTM/GMP/2014.4.

[16] Kayentao K, Garner P, Maria van Eijk A, Naidoo I, Roper C, Mulokozi A, et al. Intermittent Preventive Therapy for Malaria During Pregnancy Using 2 vs 3 or More Doses of Sulfadoxine-Pyrimethamine and Risk of Low Birth Weight in Africa. JAMA 2013; 309: 594. https://doi.org/10.1001/jama.2012.216231.

[17] Chikwasha V, Phiri I, Chimberengwa P, Bangure D, Rusakaniko S. Predictors of IPTp Uptake among Pregnant Women in in the 2010-2011 Zimbabwe Demographic and Health Survey. 2014.

[18] Ministère de la santé du Burkina Faso. Plan stratégique national de lutte contre le paludisme 2016-2020. Ouagadougou, Burkina Faso: 2016.

[19] Akinleye SO, Falade CO, Ajayi IO. Knowledge and utilization of intermittent preventive treatment for malaria among pregnant women attending antenatal clinics in primary health care centers in rural southwest, Nigeria: a cross-sectional study. BMC Pregnancy Childbirth 2009; 9: 28. https://doi.org/10.1186/1471-2393-9-28.

[20] World Health Organization. Malaria Policy Advisory Committee Meeting. 16-18 September 2015, Geneva, Switzerland: 2015. 
[21] Yaya S, Uthman OA, Amouzou A, Bishwajit G. Use of intermittent preventive treatment among pregnant women in sub-Saharan Africa: Evidence from malaria indicator surveys.
Trop
Med
Infect
Dis
2018 ;

https://doi.org/10.3390/tropicalmed3010018.

[22] Kemble SK, Davis JC, Nalugwa T, Njama-Meya D, Hopkins H, Dorsey G, et al. Prevention and treatment strategies used for the community management of childhood fever in Kampala, Uganda. Am J Trop Med Hyg 2006; 74: 999-1007. https://doi.org/10.4269/ajtmh.2006.74.999.

[23] Gikandi PW, Noor AM, Gitonga CW, Ajanga AA, Snow RW. Access and barriers to measures targeted to prevent malaria in pregnancy in rural Kenya. Trop Med Int Heal 2008; 13: 20817. https://doi.org/10.1111/j.1365-3156.2007.01992.x.

[24] Holtz TH, Patrick Kachur S, Roberts JM, Marum LH, Mkandala C, Chizani N, et al. Use of antenatal care services and intermittent preventive treatment for malaria among pregnant women in Blantyre District, Malawi. Trop Med Int Heal 2004; 9: 77-82. https://doi.org/10.1046/j.13653156.2003.01170.x.

[25] Mbonye AK, Hansen KS, Bygbjerg IC, Magnussen P. Intermittent preventive treatment of malaria in pregnancy: the incremental cost-effectiveness of a new delivery system in Uganda. Trans R Soc Trop Med Hyg 2008; 102: 685-93. https://doi.org/10.1016/j.trstmh.2008.04.016.

[26] Hill J, Hoyt J, van Eijk AM, D’Mello-Guyett L, ter Kuile FO, Steketee R, et al. Factors Affecting the Delivery, Access, and Use of Interventions to Prevent Malaria in Pregnancy in SubSaharan Africa: A Systematic Review and Meta-Analysis. PLoS Med 2013; 10. https://doi.org/10.1371/journal.pmed.1001488.

[27] Florey L. Preventing malaria during pregnancy in sub-Saharan Africa: determinants of effective IPTp delivery. DHS Anal Stud 2013: x-pp. 